\title{
PARTNERSHIP DISSOLUTION, COMPLEMENTARITY, AND INVESTMENT INCENTIVES
}

\author{
JIANPEI LI \\ ELMAR WOLFSTETTER
}

CESIFO WORKING PAPER NO. 1325

CATEGORY 9: INDUSTRIAL ORGANISATION

NOVEMBER 2004

\footnotetext{
An electronic version of the paper may be downloaded

- from the SSRN website:

www.SSRN.com

- from the CESifo website:

www.CESifo.de
} 


\title{
PARTNERSHIP DISSOLUTION, COMPLEMENTARITY, AND INVESTMENT INCENTIVES
}

\begin{abstract}
We study a partnership that anticipates its possible dissolution. In our model, partnerships form in order to take advantage of complementary skills; although new opportunities may arise that make partners' skills useless. We characterize the optimal, incentive-compatible partnership contract that can be implemented by a simple call option, and then analyze the commonly used buy-sell provision. We show that this dissolution rule gives rise to inefficiency, either in the form of excessive dissolutions combined with underinvestment or efficient dissolutions combined with overinvestment. However, supplementing the buy-sell provision with the right to veto may restore efficiency.
\end{abstract}

JEL Code: C78, D82, J12, K12, L24.

Jianpei $\mathrm{Li}$

Institut für Wirtschaftstheorie I Humboldt University of Berlin

Spandauer Str. 1

10099 Berlin

Germany

lijianpei@wiwi.hu-berlin.de
Elmar Wolfstetter

Institut für Wirtschaftstheorie I

Humboldt University of Berlin

Spandauer Str. 1

10099 Berlin

Germany

wolfstetter@wiwi.hu-berlin.de

We thank Paul Schweinzer and the participants of the SFB workshop at Gummersbach and the WZB seminar in Berlin for comments. Financial support by the Deutsche Forschungsgemeinschaft, SFB Transregio 15, "Governance and Efficiency of Economic Systems" is gratefully acknowledged. 


\section{INTRODUCTION}

Consider two agents who plan to set up a partnership to take advantage of their complementary skills. What rules should they write into the partnership contract in order to avoid expensive renegotiations and holdup in the event of a future dissolution? Should they dissolve the partnership whenever one partner makes a buyout offer? And how should they adjust their joint investment to the prospect of future dissolution? Should they underinvest in order to minimize potential losses of the partner who withdraws in the event of dissolution or overinvest in order to make the partnership "too big to fail"?

In a seminal paper, Cramton, Gibbons, and Klemperer (1987) study the partnership dissolution problem in a symmetric independent private values model. Their main result is that efficient dissolution is always possible if the initial shares are not too far from equal. Fieseler, Kittsteiner, and Moldovanu (2003) extend that model to interdependent values, and show that efficient dissolution is easier when valuations are negatively correlated, yet more difficult when they are positively correlated. Jehiel and Pauzner (2003) address the case of interdependent values with one-sided information, and conclude that even if shares are of equal size, an efficient breakup is not guaranteed.

Another branch of the literature studies the particular dissolution rule known as "buy-sell provision" or "Texas shoot-out", which is a variant of the wellknown "I-cut-you-choose" cake cutting mechanism. There, the partner who requests a dissolution must propose a price at which the other partner may either sell his share or buy the proposer's share. That rule is widely used in practice and recommended by legal advisors (see for example Mancuso and Laurence (2003)). Indeed, as Brooks and Spier (2004) report: "The importance of buy-sell agreements is now so broadly recognized that a lawyer's failure to recommend or include them in modern joint venture agreements is considered "malpractice" among legal scholars and practitioners."

Buy-sell provisions ensure ex post dissolution efficiency under complete information (McAfee (1992)) and when private information is one-sided (Samuelson (1984)). When information is incomplete, efficiency is no longer guaran- 
teed (McAfee (1992)). However, in that case efficiency may be restored when the right to be proposer of a dissolution is auctioned among partners (de Frutos and Kittsteiner (2004)).

One limitation of the partnership dissolution literature is that it takes the characteristics of the partnership and the dissolution decision as given and looks only at the issue of who shall be made single owner. It thus ignores the question whether the partnership should be dissolved at all, and how dissolution rules shape the very formation of partnerships and investment incentives (see Wolfstetter (2002)).

The possibility of a break-up affects the joint investment into the partnership, and in turn, the choice of investment affects the dissolution decision. For example, if partners expect a dissolution to occur with high probability, they may attempt to minimize the losses of the partner who withdraws from the firm in the event of a break-up, by choosing a relatively low investment, which in turn contributes to make such a break-up even more likely. Alternatively, partners may decide to go the other extreme, and overinvest into assets that increase the gains from complementarity to such an extent that a dissolution is effectively precluded. Some degree of such overinvestment is often observed in business, and is a conspicuous feature in many marital partnerships.

The present paper attempts to extend the partnership dissolution literature by analyzing the interrelationship between investment and the dissolution decision. For this purpose we introduce a simple, explicit partnership model, in which partnerships form in order to take advantage of complementary skills, as in Farrell and Scotchmer (1988). However, new opportunities may arise that make partners' skills useless, and hence trigger a request for dissolution. Anticipating that possibility of a break-up, the partnership contract includes a dissolution rule which is typically a buy-sell provision. Investment into the partnership increases the gains from complementarity, yet makes potentially efficient dissolutions less likely.

The main purpose of our analysis is to assess the commonly used buy-sell provision. Our main result is that this dissolution rule gives rise to inefficiency, either in the form of excessive dissolutions, combined with underinvestment, or efficient dissolutions, combined with overinvestment. How- 
ever, if one supplements the buy-sell provision with a right to veto, we find that efficiency may be restored. Such a right to veto is part of the legal background rules under corporate law which applies to minority shareholders in a closely-held corporation. Whereas under partnership law, any partner can initiate a dissolution and liquidation of the partnership.

The plan of the paper is as follows. In Section 2 the model is presented. In Section 3, we characterize the optimal partnership contract, characterized by joint investment and a dissolution rule, and show that there exists a simple transfer rule that implements it without employing a third-party budget breaker. This result is then used as a benchmark to assess the commonly used buy-sell provision. That rule is analyzed in Sections 4, without right to veto. We show that it gives rise to either excessive dissolutions, combined with underinvestment, or efficient dissolution, combined with overinvestment. In Section 5 we add the right to veto, and show that this may restore efficiency. Section 6 concludes.

\section{THE MODEL}

Two risk neutral agents set up a partnership in order to take advantage of their complementary capabilities. Before they pool their resources, they sign a partnership contract, $\{I, D, t\}$, that prescribes the joint investment $I$, and a dissolution, $D$, and transfer rule, $t$, that shall be applied in the event of a break-up. Both partners are equally capable, and the partnership is an equal share partnership. ${ }^{1}$

After the partnership has been put in place, one randomly chosen partner finds a new business opportunity that may be incompatible with his partner's skill. This triggers a reconsideration of the partnership, which may lead to its dissolution. ${ }^{2}$

\footnotetext{
${ }^{1}$ The empirical literature finds that roughly $80 \%$ of all partnerships have two partners, and roughly two thirds of all two-partner partnerships exhibit equal ownership (see Hauswald and Hege (2003)).

${ }^{2}$ In business practice, there are many other events that may trigger a dissolution, such as: 1) an offer from an outsider to purchase a partner's share; 2) a divorce settlement in which a partner's ex spouse receives a share in the firm; 3) a foreclosure of debt secured
} 
The partnership game is a sequential game.

In stage one, the two partners write the contract $\{I, D, t\}$, set up the partnership, and share the (irreversible) investment cost $C(I): C(I):=\frac{1}{2} I^{2}$.

In stage two, nature draws one of the partners, with probability $1 / 2$, and endows him with a new business opportunity, drawn from a given probability distribution, $q_{s}:=\operatorname{Pr}\{S=s\}$, defined on the states of the world. The partner who receives that new opportunity may then request a break-up, which is then executed according to the rules $\{D, t\}$.

The partner who has received the new business opportunity is referred to as partner 1 ; the other as partner 2 .

The new opportunity is either compatible or incompatible with the partners' skills, and it gives rise to a profit shock $\Pi \in\{0, \pi\}, \pi>0$.

After it has been determined who is partner 1 , the random events are described by the three states of the world: $\Theta:=\{t h, n h, l\}$. There, $t$, resp. $n$ (mnemonic for "team" resp. "no team") denotes that the innovation is compatible resp. incompatible with the partner's skill, and $h, l$ indicate that the profit shock is either high, $\Pi=\pi$, or low, $\Pi=0$.

If the partnership stays together, each partner earns one half of the gross value of the firm, $V_{p}(I, s)$ :

$$
V_{p}(I, s):= \begin{cases}(1+\alpha) I+\pi & \text { if } s=t h \\ (1+\alpha) I & \text { if } s \neq t h\end{cases}
$$

where $\alpha>0$ is a measure of the complementarity of partners' skills.

Whereas, if the partnership is dissolved, the benefit of complementarity is lost, and the firm's value is either $V_{1}(I, s)$ or $V_{2}(I, s)$, if partner 1 , resp. partner 2, becomes single owner:

$$
\begin{aligned}
& V_{1}(I, s):=\left\{\begin{array}{lll}
I+\pi & \text { if } & s \in\{t h, n h\} \\
I & \text { if } & s \in\{l\}
\end{array}\right. \\
& V_{2}(I, s):=I, \quad \text { for all } s \in \Theta .
\end{aligned}
$$

by a partner's share; 4) the personal bankruptcy of a partner; 5) the disability or death or incapacity of a partner. These other events are ignored in the present model. 
The parameters $(\alpha, \pi)$ are constrained as follows: ${ }^{3}$

$$
\alpha>0, \quad \pi \geq \alpha\left(1+\alpha\left(1-\frac{1}{2} q_{n h}\right)\right)=: \tilde{\pi}(\alpha),
$$

and $q_{s}: \Theta \rightarrow[0,1], \sum_{s \in \Theta} q_{s}=1$, has full support.

\section{IMPLEMENTATION OF THE OPTIMAL INVESTMENT AND DISSOLUTION RULE}

We now characterize the first-best optimal allocation, and show that it can be implemented without employing a third-party budget breaker. This result serves as a benchmark to assess commonly used dissolution rules.

Let $\mu_{i}^{*}(s):=\operatorname{Pr}\{$ partner i becomes single owner $\mid s\}, i \in\{1,2\}$.

LEMMA 1 The efficient (direct) dissolution rule, $D^{*}:=\left\{\mu_{1}^{*}(s), \mu_{2}^{*}(s)\right\}$, and joint investment, $I^{*}$, are

$$
\begin{aligned}
\mu_{1}^{*}(n h)=1, \quad \mu_{1}^{*}(s) & =0, \forall s \neq n h, \quad \mu_{2}^{*}(s)=0, \forall s \in \Theta \\
I^{*} & =1+\alpha\left(1-q_{n h}\right) .
\end{aligned}
$$

PROOF If the partnership is dissolved, single ownership shall be awarded to partner 1 , because $V_{1}(I, s) \geq V_{2}(I, s)$; therefore, $\mu_{2}^{*}(s)=0, \forall s$.

It is obviously not efficient to award single ownership to partner 1 in states $s \in\{t h, l\}$, yet efficient to do so in state $s=n h$, provided investment is sufficiently low. The critical value of investment below which dissolution pays in state $s=n h$, defined by: $V_{p}(\tilde{I}, s)=V_{1}(\tilde{I}, s)$, is $\tilde{I}:=\frac{\pi}{\alpha}$. Therefore,

$$
\mu_{1}(I, s)= \begin{cases}1 & \text { if } s=n h \text { and } I \leq \tilde{I}:=\frac{\pi}{\alpha} \\ 0 & \text { otherwise. }\end{cases}
$$

By assumption (4),

$$
\tilde{I}:=\frac{\pi}{\alpha} \geq \frac{\tilde{\pi}(\alpha)}{\alpha}=1+\alpha\left(1-\frac{1}{2} q_{n h}\right)>1+\alpha\left(1-q_{n h}\right)=: I^{*} .
$$

\footnotetext{
${ }^{3}$ The assumption concerning $\pi$ assure that a dissolution is efficient if and only if $s=n h$ occurs. If it did not hold, the first-best optimal contract would never call for dissolution.
} 
Therefore, (7) and (8) imply $\mu_{1}\left(I^{*}, s\right)=\mu_{1}^{*}(s)$.

Finally, we confirm that the optimal investment is indeed equal to $I^{*}$. Given the dissolution rule (7), the ex ante net value of the firm is

$$
\begin{aligned}
V^{*}(I) & :=E_{S}\left[\mu_{1}(I, S) V_{1}(I, S)+\left(1-\mu_{1}(I, S)\right) V_{p}(I, S)\right]-C(I) \\
& = \begin{cases}(1+\alpha) I+q_{t h} \pi-\frac{I^{2}}{2}=: \psi_{1}(I) & \text { if } I \geq \tilde{I} \\
(1+\alpha) I+\left(q_{t h}+q_{n h}\right) \pi-q_{n h} \alpha I-\frac{I^{2}}{2}=: \psi_{2}(I) & \text { if } I \leq \tilde{I} .\end{cases}
\end{aligned}
$$

Due to (8), (4), and the strict concavity of $\psi_{1}, \psi_{2}$

$$
\begin{aligned}
I_{1} & :=\underset{I \geq \tilde{I}}{\arg \max } \psi_{1}(I)=\max \{1+\alpha, \tilde{I}\} \geq \tilde{I}>I^{*}=\underset{I \leq \tilde{I}}{\arg \max } \psi_{2}(I) \\
\psi_{1}\left(I_{1}\right) & \leq \psi_{1}(1+\alpha) \\
& =\frac{(1+\alpha)^{2}}{2}+q_{t h} \pi+q_{n h}\left(\tilde{\pi}(\alpha)-\alpha\left(1+\alpha\left(1-\frac{1}{2} q_{n h}\right)\right)\right) \\
& \leq \psi_{2}\left(I^{*}\right), \quad \text { since } \tilde{\pi}(\alpha) \leq \pi .
\end{aligned}
$$

Therefore, $I=I^{*}$ is the maximizer of $V^{*}(I)$, as asserted.

PRoposition 1 The direct mechanism $\left\{I^{*}, D^{*}, t^{*}\right\}$, with the transfer $t^{*}(s)$ to be paid from partner 1 to 2 :

$$
t^{*}(s)= \begin{cases}\frac{1}{2}\left((1-\alpha)\left(1+\alpha\left(1-q_{n h}\right)\right)+\pi\right) & \text { if } s=n h \\ 0 & \text { otherwise }\end{cases}
$$

implements the first-best optimum and is budget balancing.

PROOF Given the dissolution rule $D^{*}$, partner 1 cannot arbitrarily distort the truth, because in certain states it becomes obvious that the misreported profit opportunity is not available. Specifically, 1) if the true state is $s=n h$, partner 1 would be found out to lie if he reported $\bar{s}=t h$; therefore, the transfer rule only needs to deter him from reporting $\bar{s}=l$. Similarly, 2) if $s=l$, the transfer rule only needs to prevent reporting $\bar{s}=n h$; and 3 ), if $s=t h$, it needs to prevent reporting $\bar{s} \in\{n h, l\}$. 
1) If $s=n h$, partner 1's payoff from truthtelling is $u(s, s):=I^{*}+\pi-t^{*}(n h)$, whereas reporting $\bar{s}=l$ gives him $u(s, \bar{s}):=\frac{1}{2}(1+\alpha) I^{*}$. Since $u(s, s)-$ $u(s, \bar{s})=\pi / 2>0$, distorting the truth does not pay.

2)-3): The proofs are similar, and hence omitted.

Finally, the mechanism is budget balancing, because the transfer $t^{*}$ is a payment between partners.

COROLLARY 1 The direct mechanism $\left(I^{*}, D^{*}, t^{*}\right)$ can be interpreted as a contingent ownership contract where the state contingent dissolution rule is replaced by a simple call option. That option gives each partner the right to buy the other's share at a strike price that is equal to $t^{*}(n h)$.

This result is in line with Grossman and Hart (1986) and Nöldeke and Schmidt (1998). In the practical literature, finding the right strike price is usually considered to be too difficult. Instead, partners are advised to employ a price-finding rule, like a buy-sell provision.

\section{BUY-SELL PROVISION WITHOUT RIGHT TO VETO}

We now assume that the partnership contract includes a buy-sell provision, without right to veto. There, partner 1 may propose dissolution, ${ }^{4}$ and if he does, he must quote a price at which the other partner may either sell his share or buy the proposer's share. We analyze the resulting partnership game, and find the perfect equilibrium partnership contract.

\subsection{Dissolution subgame equilibrium}

After joint investment has been made, and the state of the world $s \in \Theta$ has been realized and privately observed by partner 1, the two partners play the dissolution subgame. That game depends critically on the level of

\footnotetext{
${ }^{4}$ Following Samuelson (1984), we let the player with more information be the proposer; this guarantees that the assignment of single ownership always maximizes the firm's value.
} 
investment. As one would expect, if investment is very high, a dissolution is effective precluded. Thus, a high investment can be interpreted as a "toobig-to-fail" policy. Whereas a low level of investment gives rise to excessive dissolutions.

The strategies of partner 1 are denoted by $\sigma_{1}(I, s):=\left(\tau_{1}(I, s), p(I, s)\right)$, where $\tau_{1}(I, s):=\operatorname{Pr}\{$ propose $\mid I, S=s\}$, and $p(I, s)$ is the price quoted if a breakup is proposed in state $s$. In turn, the strategy of partner 2 is his buy-sell decision, contingent upon the quoted price $p$, denoted by $\sigma_{2}(p):=$ $\operatorname{Pr}\{$ sell $\mid p\}$, where it is understood that $1-\sigma_{2}(p)=\operatorname{Pr}\{$ buy $\mid p\}$.

The solution of the dissolution subgame is explained in the following Lemmas.

LEMMA 2 Partner 2 sells if and only if $p \geq p^{*}:=I / 2$, and partner 1 quotes the price $p(s)=p^{*}$, if he proposes dissolution.

Proof Suppose partner 1 has proposed dissolution and quoted the price $p$. If partner 2 buys, he earns the payoff $V_{2}(I, s)-p=I-p$, whereas if he sells he earns $p$. Therefore, he sells if and only if $p \geq I / 2$. In turn, if partner 1 buys at price $p^{*}$ he earns $V_{1}(I, s)-p^{*} \geq \frac{I}{2}$, whereas if he sells at price $p<p^{*}$ he earns only $p<\frac{I}{2}$. Therefore, if he proposes, he quotes the price $p=p^{*}$.

We now show that the equilibrium of the dissolution subgame depends on the level of investment.

LEMMA 3 The dissolution subgame has the following equilibrium:

$$
\begin{gathered}
\sigma_{1}(I, s)=\left(p^{*}, \tau_{1}(I, s)\right), \tau_{1}(I, s)= \begin{cases}1 & \text { if } s \in \Theta_{1}(I) \\
0 & \text { otherwise }\end{cases} \\
\sigma_{2}(p)= \begin{cases}1 & \text { if } p \geq p^{*} \\
0 & \text { otherwise. }\end{cases} \\
\Theta_{1}(I)= \begin{cases}\varnothing & \text { if } I \geq 2 \tilde{I} \\
\{n h\} & \text { if } I \in[\tilde{I}, 2 \tilde{I}) \\
\{n h, t h\} & \text { if } I \in[0, \tilde{I})\end{cases}
\end{gathered}
$$


Proof The equilibrium strategy $\sigma_{2}(p)$ and equilibrium price $p^{*}$ have already been established in Lemma 2 . To confirm that $\tau_{1}(I, s)$ is part of partner 1's equilibrium strategy, note that

$$
\begin{aligned}
& \frac{1}{2} V_{P}(I, t h) \gtreqless V_{1}(I, t h)-\frac{I}{2} \Longleftrightarrow I \gtreqless \tilde{I} \\
& \frac{1}{2} V_{P}(I, n h) \gtreqless V_{1}(I, n h)-\frac{I}{2} \Longleftrightarrow I \gtreqless 2 \tilde{I}
\end{aligned}
$$

Therefore, $\tilde{I}$ can be interpreted as the smallest investment that deters dissolution in state $s=t h$, and $2 \tilde{I}$ as the smallest investment that deters dissolution in all states.

\subsection{Perfect Bayesian Nash equilibrium}

To find the Perfect Bayesian Nash equilibria of the entire game, we compute the ex ante net value of the firm, for all choices of $I$, using the corresponding equilibrium of the above subgame (recall the definitions of $\psi_{1}, \psi_{2}$ in (9)):

$$
\begin{aligned}
V(I): & =E_{S}\left[\tau_{1}(I, S) V_{1}(I, S)+\left(1-\tau_{1}(I, S)\right) V_{p}(I, S)\right]-C(I) \\
& =\left\{\begin{array}{lll}
\psi_{1}(I) & \text { if } \quad I \geq 2 \tilde{I} \\
\psi_{2}(I) & \text { if } \quad I \in[\tilde{I}, 2 \tilde{I}) \\
\psi_{3}(I):=\psi_{2}(I)-q_{t h} \alpha I & \text { if } \quad I \in[0, \tilde{I})
\end{array}\right.
\end{aligned}
$$

In a first step we show that equilibrium investment is bounded from above and from below. In particular, the "too-big-to-fail" policy is not part of the equilibrium.

LEMMA 4 The optimal investment is $I \in\{\hat{I}, \tilde{I}\}$, where

$$
\hat{I}:=\underset{I \in[0, \tilde{I})}{\arg \max } \psi_{3}(I)=1+\alpha-\left(q_{n h}+q_{t h}\right) \alpha<I^{*}<\tilde{I} .
$$


Proof The optimal investment is the maximizer of either $\psi_{3}$ on $[0, \tilde{I})$ or $\psi_{2}$ on $[\tilde{I}, 2 \tilde{I})$ or $\psi_{1}$ on $[2 \tilde{I},+\infty)$. All three functions, $\psi_{3}, \psi_{2}, \psi_{1}$ are strictly concave.

First, note that $\hat{I}$ is the maximizer of $\psi_{3}$ on its domain, because $\psi_{3}^{\prime}(\hat{I})=0$, and (using (8))

$$
\hat{I}=1+\alpha-\left(q_{n h}+q_{t h}\right) \alpha<1+\alpha-q_{n h} \alpha=I^{*}<\tilde{I}
$$

Second, $\tilde{I}$ is the maximizer of $\psi_{2}$ on its domain, since $\psi_{2}^{\prime}(\tilde{I})<0$.

Third, $2 \tilde{I}$ is the maximizer of $\psi_{1}$ on its domain, since $\psi_{1}^{\prime}(2 \tilde{I})<0$.

Finally, observe that:

$$
\begin{aligned}
\psi_{3}(\hat{I})-\psi_{1}(2 \tilde{I}) & =\frac{4 \pi}{2 \alpha^{2}}\left(\pi-\alpha\left(1+\alpha-\frac{1}{2} q_{n h} \alpha\right)\right)+\frac{1}{2}\left(1+q_{l} \alpha\right)^{2} \\
& \geq \frac{1}{2}\left(1+q_{l} \alpha\right)^{2}>0, \quad \text { since } \pi \geq \tilde{\pi}(\alpha)
\end{aligned}
$$

Therefore, $I=2 \tilde{I}$ is dominated by $I=\hat{I}$.

\section{LEMMA 5 The optimal investment is}

$$
\begin{aligned}
& I=\hat{I} \Longleftrightarrow(\pi, \alpha) \in \mathcal{P}_{+}:=\left\{(\pi, \alpha) \mid \pi \geq \max \left\{\pi_{0}(\alpha), \tilde{\pi}(\alpha)\right\}\right\} \\
& I=\tilde{I} \Longleftrightarrow(\pi, \alpha) \in \mathcal{P}_{-}:=\left\{(\pi, \alpha) \mid \tilde{\pi}(\alpha) \leq \pi<\max \left\{\pi_{0}(\alpha), \tilde{\pi}(\alpha)\right\}\right\} .
\end{aligned}
$$

Proof To determine whether $\hat{I}$ or $\tilde{I}$ is optimal, compute the payoff difference

$$
\begin{aligned}
\xi(\pi) & :=\psi_{3}(\hat{I})-\psi_{2}(\tilde{I}) \\
& =\frac{1}{2 \alpha^{2}}\left(\pi^{2}-2 \pi \alpha\left(1+\left(1-q_{n h}\right) \alpha\right)+\alpha^{2}\left(1+\left(1-q_{t h}-q_{n h}\right) \alpha\right)^{2}\right)
\end{aligned}
$$

The following equation implicitly defines the set of parameters $(\pi, \alpha)$ for which $\xi(\pi)=0$ :

$$
\pi_{0}(\alpha):=\tilde{\pi}(\alpha)-\frac{1}{2} q_{n h} \alpha^{2}+\sqrt{q_{t h} \alpha^{3}\left(2+2 \alpha-2 q_{n h} \alpha-q_{t h} \alpha\right)} .
$$

Since $\xi$ is increasing in $\pi$ for all feasible parameters, $\pi \geq \tilde{\pi}(\alpha)$, it follows immediately that $\hat{I}$ is optimal if and only if $\pi \geq \pi_{0}(\alpha)$ and $\pi \geq \tilde{\pi}(\alpha)$. 
The two parameter sets, $\mathcal{P}_{+}, \mathcal{P}_{-}$are illustrated in Figure 1 . There, the area under the dotted curve is the set of parameters that are not feasible (due to the constraint (4)), the area below the solid and at or above the dotted curve is the parameter set $\mathcal{P}_{-}$, and the area at and above the solid curve is $\mathcal{P}_{+}$.

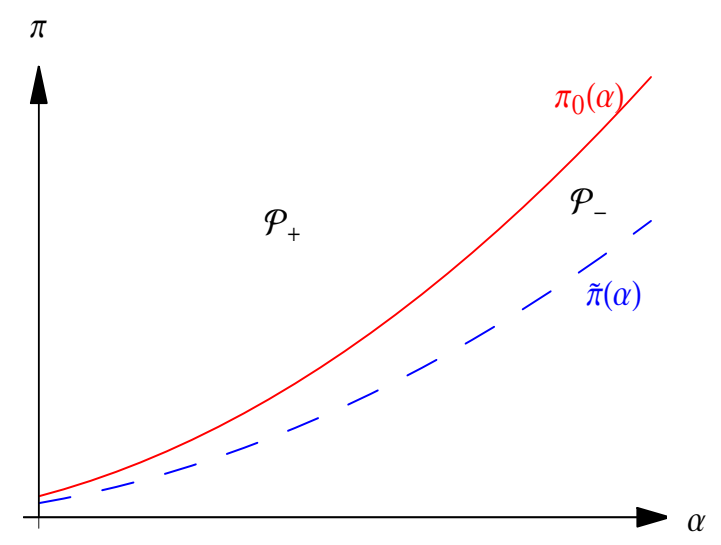

Figure 1: Parameter sets $\mathcal{P}_{+}, \mathcal{P}_{-}$

Combining Lemmas 3-5, we conclude:

Proposition 2 The perfect equilibrium exhibits:

1. Excessive dissolution (in $s \in\{n h$, th $\}$ ) and underinvestment, $I=\hat{I}<I^{*}$, $\forall(\pi, \alpha) \in \mathcal{P}_{+}$.

2. Efficient dissolution and overinvestment, $I=\tilde{I}>I^{*}, \forall(\pi, \alpha) \in \mathcal{P}_{-}$.

We close this section with two examples:

EXAMPLE 1 Let $\left\{\alpha=1,5, \pi=6.1, q_{n h}=0,5, q_{t h}=0,25\right\}$. This leads to excessive dissolution, combined with underinvestment (illustrated in Figure 2). 


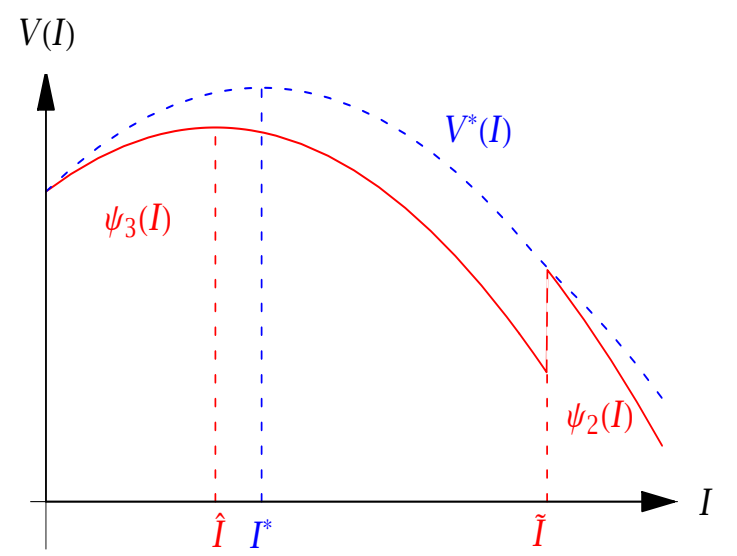

Figure 2: Excessive dissolution and underinvestment

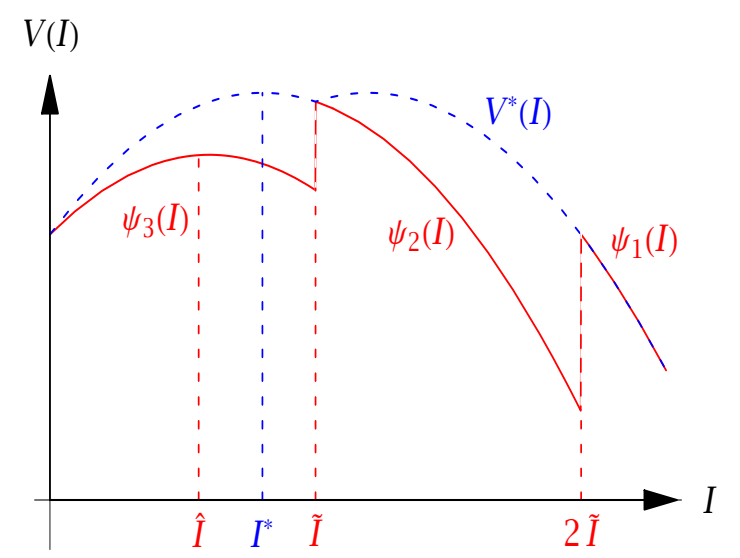

Figure 3: Efficient dissolution and overinvestment 
EXAMPLE 2 Let $\left\{\alpha=3, \pi=12, q_{n h}=0,5, q_{t h}=0,25\right\}$. This leads to efficient dissolution, combined with overinvestment (illustrated in Figure 3).

We conclude with a remark on an alternative specification of the partnership technology.

To show that our results are not restricted to the specification adopted here, replace $V_{p}(I, t h)$ in $(1)$ by $V_{p}(I, t h):=(1+\alpha)(I+\pi)$. In that case, the incentive to dissolve is weaker, and the buy-sell provision does not always lead to inefficiency. However, we also find conditions for inefficiency, either in the form of excessive dissolution, combined with underinvestment, or efficient dissolution, combined with overinvestment.

Now, the smallest investment that deters dissolution in state $s=t h$ is equal to $\tilde{I}(1-\alpha)$ (rather than equal to $\tilde{I})$. Otherwise, the role and exact meaning of the critical investment levels $I^{*}, \tilde{I}, \hat{I}, 2 \tilde{I}$ is unchanged. We find that inefficiency occurs if and only if $\alpha<1$ and $I^{*} \in(\hat{I}, \tilde{I}(1-\alpha))$, where the two kinds of inefficiencies occur in subsets of the parameters space that are similar to the ones illustrated in Figure 1.

\section{BUY-SELL PROVISION WITH RIGHT TO VETO}

We now change the buy-sell provision by granting partner 2 the right to veto a proposed dissolution. This modification transforms the dissolution subgame into a signalling game in which the quoted price serves as a signal of partner 1's private information, and partner 2 uses that signal to update his prior beliefs concerning the value of the partnership, in order to assess whether he should either sell his share or veto and thus keep the partnership going.

In the following we employ the concept of a sequential equilibrium, characterized by strategies, and beliefs that are consistent with those strategies. With slight abuse of language, we will refer to the game played after a buysell provision has been offered as the dissolution "subgame". 


\subsection{Dissolution subgame}

In the dissolution subgame with right to veto, the action set of partner 2 has three elements: "buy", "sell", and "veto". And partner 1 chooses between "propose" a buy-sell provision and "don't propose". However,

LEMMA 6 The dissolution subgame can be reduced to one where partner 1 always proposes, and quotes a price $p \geq \frac{I}{2}$; and partner 2 only chooses between "sell" and "veto" (and never contemplates to "buy").

Proof 1) Observe that partner 2 will always veto, if partner 1 offers a price $p \in\left[\frac{I}{2}, \frac{I}{2}(1+\alpha)\right]$, because veto gives him a payoff equal to $\frac{I}{2}(1+\alpha)$ or more. Therefore, "don't propose" is payoff equivalent to proposing a price $p \in\left[\frac{I}{2}, \frac{I}{2}(1+\alpha)\right]$. We conclude that we can represent "don't propose" by "propose" a price from that interval.

2) Observe that if partner 1 proposes a price $p<\frac{I}{2}$, partner 2 will either buy or veto, since buying is better than selling in that case. Instead of selling at such a price, partner 1 prefers to maintain the partnership. Therefore, in the light of 1 ), proposing a price $p<\frac{I}{2}$ is inferior to proposing a price $p \in\left[\frac{I}{2}, \frac{I}{2}(1+\alpha)\right]$. We conclude that partner 1 will always propose and quote a price $p \geq \frac{I}{2} .^{5}$

In that reduced game, the strategy of partner 1 is his probability of quoting a price $p$, denoted by $\sigma_{1}(p ; s, I):=\operatorname{Pr}\{P=p \mid S=s\}$, with some support $\mathcal{P}$. The strategy of partner 2 is $\sigma_{2}(p ; I)=\operatorname{Pr}\{$ sell $\mid p\}$ and $1-\sigma_{2}(p ; I)=\operatorname{Pr}\{$ veto $\mid$ $p\}$. And the beliefs of partner 2 are denoted by $\delta_{s}(p, I):=\operatorname{Pr}\{S=s \mid p\}$.

The equilibrium of the subgame depends on the level of investment; four intervals must be distinguished:

$$
\begin{gathered}
I_{1}:=\left[0, \frac{q_{n h} \tilde{I}}{2\left(q_{t h}+q_{n h}\right)}\right], \quad I_{2}:=\left(\frac{q_{n h} \tilde{I}}{2\left(q_{t h}+q_{n h}\right)}, \frac{\tilde{I}}{2}\right) \\
I_{3}:=\left[\frac{\tilde{I}}{2}, \tilde{I}\right), \quad I_{4}:=[\tilde{I},+\infty) .
\end{gathered}
$$

\footnotetext{
${ }^{5}$ If $\alpha>1$, this argument can be simplified, because in that case "veto" dominates "buy".
} 
PROPOSITION 3 The dissolution subgame has a "partial separating equilibrium". There, dissolution occurs:

1) never if $I$ is "high": $I \in I_{4}$,

2) only in state $n h$ if $I \in I_{3}$,

3) in state nh and with positive probability less than one also in state th if $I \in I_{2}$,

4) in states $n h$ and th if $I$ is "low": $I \in I_{1}$.

A detailed formulation and proof of Proposition 3 is in the Appendix.

As in other signaling games, there are, however, also other equilibria, with different properties.

PROPOSITION 4 The dissolution subgame has a "partial pooling equilibrium". There, for all investment levels $I \in I_{3} \cup I_{4}$, all types $s$ quote the same price, at which partner 2 vetoes, and no dissolution occurs.

The detailed formulation and proof of Proposition 4 is also in the Appendix.

\subsection{Perfect Bayesian Nash equilibrium}

We now show that, when partner 2 has the right to veto, the overall game has a perfect equilibrium, for some subset of the feasible parameters, that implements the efficient investment and dissolution rule.

Proposition 5 Suppose $\pi<2 \tilde{\pi}(\alpha)-\alpha q_{n h} \cdot{ }^{6}$ Then, the partial separating equilibrium implements the efficient investment and dissolution rule.

Proof For those parameters, one has $I^{*} \in I_{3}$. By definition of $I^{*}$, the ex ante net value of the firm is maximized, provided dissolution occurs if and only if $s=n h$. In the partial separating equilibrium, that condition is satisfied for all $I \in I_{3}$, and therefore, for $I=I^{*}$.

\footnotetext{
${ }^{6}$ Recall, the set of feasible $(\pi, \alpha)$ is $\{(\pi, \alpha) \mid \pi \geq \tilde{\pi}(\alpha)\}$.
} 
However, for the same parameters, there is also another equilibrium that entails inefficiency.

PROPOSITION 6 For the same parameter restriction assumed in Proposition 5 the partial pooling equilibrium implies inefficiency.

Proof Suppose the partners play partial pooling equilibrium of the dissolution subgame, and choose the efficient investment level $I=I^{*}$. Then, by Proposition 4, all types quote the same price at which partner 2 vetoes; therefore, no dissolution occurs, which is inefficient.

However, standard equilibrium refinements select the equilibrium in which partner 1 reveals his private information, which restores efficiency (see Banks and Sobel (1987) and Cho and Kreps (1987)).

As we have seen, adding the right to veto to the buy-sell provision is attractive because it may restore efficiency. In addition, it seems that the right to veto is also crucial to prevent an obvious hold-up problem, where one partner finds another partner who may be satisfied with a smaller share, after the partnership capital has been built up. This hold-up problem may also explain why the practical literature discourages the use of the kind of option contract stated at the end of Section 3.

\section{CONCLUSIONS}

In this paper, we extended the partnership dissolution literature, initiated by Cramton et al. (1987), by setting up an explicit model of partnerships that may explain why partnerships form, and yet dissolve in the face of new business opportunities. We analyzed the effect of the commonly advised and frequently used dissolution rule, known as buy-sell provision. That rule assures that, conditional on dissolution, the assignment of single ownership is efficient. However, if that rule does not include the right to veto a proposed dissolution, it always entails an efficiency loss, either in the form of excessive dissolutions, combined with underinvestment, or efficient dissolution, combined with overinvestment. When the right to veto is added, 
efficiency may be restored, although it gives rise to an equilibrium selection problem.

\section{APPENDIX}

Here we give detailed statements and proofs of Propositions 3 and 4 .

PROPOSITION 3 The equilibrium strategies and beliefs of the "partial separating equilibrium" are:

Strategies:

$$
\begin{gathered}
\sigma_{1}\left(\hat{p}(I) ; \text { th,I) }:=\eta(I), \quad \sigma_{1}\left(p_{2} ; t h, I\right):=1-\eta(I)\right. \\
\sigma_{1}(\hat{p}(I) ; n h, I):=1, \quad \sigma_{1}\left(p_{1} ; l, I\right):=1 \\
\frac{I}{2} \leq p_{1}<p_{2}<\frac{(1+\alpha) I}{2} \leq \hat{p}(I):=\frac{1}{2}\left(I(1+\alpha)+\delta_{t h}(\hat{p}(I)) \pi\right) \\
\sigma_{2}(p ; I)= \begin{cases}1 \quad \text { if } p>\hat{p}(I) \quad \text { or } \quad(p=\hat{p}(I) \quad \text { and } I<\tilde{I}) \\
0 \text { otherwise }\end{cases} \\
\eta(I):=\left\{\begin{array}{lll}
0 & \text { if } I \in I_{3} \cup I_{4} \\
\frac{q_{n h}(\pi-2 \alpha I)}{2 q_{t h} \alpha I} & \text { if } \quad I \in I_{2} \\
1 & \text { if } I \in I_{1}
\end{array}\right.
\end{gathered}
$$

Beliefs:

$$
\begin{aligned}
\delta_{t h}(p, I) & := \begin{cases}1 & \text { if } p \in\left[p_{2}, \hat{p}(I)\right) \\
\frac{q_{t h} \sigma_{1}(\hat{p}(I) ; t h, I)}{q_{n h}+q_{t h} \sigma_{1}(\hat{p}(I) ; t h, I)} & \text { if } p=\hat{p}(I) \\
0 & \text { if } p<p_{2} \text { or } p>\hat{p}(I)\end{cases} \\
\delta_{n h}(p, I) & :=\left\{\begin{array}{lll}
1 & \text { if } p>\hat{p}(I) \\
\frac{q_{n h}}{q_{n h}+q_{t h} \sigma_{1}(\hat{p}(I) ; t h, I)} & \text { if } p=\hat{p}(I) \\
0 & \text { if } p<\hat{p}(I)
\end{array}\right. \\
\delta_{l}(p, I) & := \begin{cases}1 & \text { if } p<p_{2} \\
0 & \text { otherwise }\end{cases}
\end{aligned}
$$


Proof The beliefs are obviously consistent with the stated strategies, using Bayes' rule, when it applies. Also, partner 2's strategy is evidently a best reply, given his beliefs. It remains to be shown that partner 1's strategies are best replies, given the beliefs $\delta(p, I)$, for all investment levels.

$1)$ Suppose $I \in I_{4}$. Then, $\eta(I)=0, \sigma_{1}(\hat{p}(I) ; n h, I)=\sigma_{1}\left(p_{2} ; t h, I\right)=\sigma_{1}\left(p_{1} ; l, I\right)=$ $1, \sigma_{2}(p)=1$ if $p>\hat{p}(I)$ and $\sigma_{2}(p ; I)=0$ for all other $p, \delta_{t h}(\hat{p}(I) ; I)=0$, $\delta_{n h}(\hat{p}(I) ; I)=1$, and $\hat{p}(I)=\frac{1}{2} V_{p}(I, n h)$.

Consider type $s=n h$. In the asserted equilibrium, he shall quote the price $\hat{p}(I)$ with certainty. If he deviates, he can only change the outcome if he quotes a higher price, $p$. However, this does not pay, since the gain from that deviation is negative:

$$
\begin{aligned}
I+\pi-p-\frac{1}{2} V_{p}(I, n h) & <I+\pi-V_{p}(I, n h) \\
& =I+\pi-(1+\alpha) I \\
& =\pi-\alpha I \\
& \leq \pi-\alpha \tilde{I} \quad(\text { since } I \geq \tilde{I}) \\
& =0 \quad(\text { by definition of } \tilde{I}) .
\end{aligned}
$$

Consider $s=t h$. In the asserted equilibrium, partner 1 proposes the price $p_{2}$, and partner 2 vetoes. If partner 1 deviates, he can only change the outcome by proposing a price $p>\hat{p}$, at which partner 2 sells, just like in the above case $s=n h$. Evidently, maintaining the partnership is more profitable than in the event $s=n h$. Therefore, such a deviation is even less profitable than in the case $s=n h$, described above.

Consider $s=l$. In the asserted equilibrium, partner 1 proposes the price $p_{1}$, and partner 2 vetoes. Again, partner 1 can only make a difference if he quotes a price $p>\hat{p}(I)$, which pays even less for him than in the cases described above.

2) Suppose $I \in I_{3}$. Then, $\eta(I)=0, \sigma_{1}(\hat{p}(I) ; n h, I)=\sigma_{1}\left(p_{2} ; t h, I\right)=\sigma_{1}\left(p_{1} ; l, I\right)=$ $1, \sigma_{2}(p)=1$ if $p \geq \hat{p}(I)$ and $\sigma_{2}(p ; I)=0$ for all other $p, \delta_{t h}(\hat{p}(I) ; I)=0$, $\delta_{n h}(\hat{p}(I) ; I)=1$, and $\hat{p}(I)=\frac{1}{2} V_{p}(I, n h)$.

Consider type $s=n h$. In the asserted equilibrium, he shall quote the price $\hat{p}(I)$, at which partner 2 sells. If partner 1 deviates, he can only change the 
outcome by quoting a lower price, $p<\hat{p}(I)$. However, this does not pay, since the gain from that deviation is negative:

$$
\begin{aligned}
\frac{1}{2} V_{p}(I, n h)-\left(I+\pi-\frac{1}{2} V_{p}(I, n h)\right) & =V_{p}(I, n h)-(I+\pi) \\
& =\alpha I-\pi \\
& <\alpha \tilde{I}-\pi \quad(\text { since } I<\tilde{I}) \\
& =0 \quad \text { (by definition of } \tilde{I}) .
\end{aligned}
$$

Consider $s=t h$. In the asserted equilibrium, partner 1 proposes the price $p_{2}$, and partner 2 vetoes. If partner 1 deviates, he can only change the outcome by proposing a price $p \geq \hat{p}$, at which partner 2 sells. However, the gain from such a deviation is negative, since

$$
\begin{aligned}
(I+\pi-p)-\frac{1}{2} V_{p}(I, t h) & \leq \frac{\pi}{2}-\alpha I \\
& \leq \frac{1}{2}(\pi-\alpha \tilde{I}) \quad\left(\text { since } I \geq \frac{\tilde{I}}{2}\right) \\
& =0 \quad(\text { by definition of } \tilde{I}) .
\end{aligned}
$$

Consider $s=l$. In the asserted equilibrium, partner 1 proposes the price $p_{1}$, and partner 2 vetoes. Again, partner 1 can only make a difference if he quotes a price $p=\hat{p}(I)$, which pays even less for him than in the previous case.

3) Suppose $I \in I_{2}$. Then, $\eta(I)=\frac{q_{n h}(\pi-2 \alpha I)}{2 q_{t h} \alpha I}, \sigma_{1}(\hat{p}(I) ; n h, I)=\sigma_{1}\left(p_{1} ; l, I\right)=$ $1, \sigma_{1}(\hat{p}(I) ; t h, I)=\eta, \sigma_{1}\left(p_{2} ; t h, I\right) \stackrel{2 q t h \alpha I}{=} 1-\eta, \sigma_{2}(p)=1$ if $p \geq \hat{p}(I)$ and $\sigma_{2}(p ; I)=0$ for all other $p, \delta_{t h}(\hat{p}(I) ; I)=1-\frac{2 \alpha I}{\pi}, \delta_{n h}(\hat{p}(I) ; I)=\frac{2 \alpha I}{\pi}$, and $\hat{p}(I)=\frac{1}{2}(I(1-\alpha)+\pi)$.

Consider type $s=n h$. In the asserted equilibrium, he shall quote the price $\hat{p}(I)$, at which partner 2 sells. If partner 1 deviates, he can only change the outcome by quoting a lower price, $p<\hat{p}(I)$. However, this does not pay, since the gain from that deviation is negative:

$$
\frac{I(1+\alpha)}{2}-(I+\pi-\hat{p}(I))=-\frac{\pi}{2}<0 .
$$


Consider $s=t h$. In the asserted equilibrium, partner 1 randomizes between the prices $p_{2}$ and $\hat{p}$, partner 2 vetoes if $p=p_{2}$ and sells if $p=\hat{p}(I)$. For that to be an equilibrium, partner 1 must be indifferent between these two actions, which confirms:

$$
\frac{1}{2}((1+\alpha) I+\pi)-(I+\pi-\hat{p}(I))=0 .
$$

If he deviates, that can only make a difference if he quotes either a price lower than $p_{1}$ (but those prices are dominated and were already eliminated in Lemma 6 ) or a price above $\hat{p}(I)$, which is obviously not an improvement either.

Consider $s=l$. In the asserted equilibrium, partner 1 proposes the price $p_{1}$, and partner 2 vetoes. Partner 1 can only make a difference if he quotes a price $p=\hat{p}(I)$. However, the gain from that deviation is negative:

$$
I-\hat{p}(I)-\frac{I(1+\alpha)}{2}=-\frac{\pi}{2}<0 .
$$

4) Suppose $I \in I_{1}$. Then, $\eta(I)=1, \sigma_{1}(\hat{p}(I) ; n h, I)=\sigma_{1}\left(p_{1} ; l, I\right)=\sigma_{1}(\hat{p}(I) ; t h, I)=$ $1, \sigma_{2}(p)=1$ if $p \geq \hat{p}(I)$ and $\sigma_{2}(p ; I)=0$ for all other $p, \delta_{t h}(\hat{p}(I) ; I)=$ $\frac{q_{t h}}{q_{n h}+q_{t h}}, \delta_{n h}(\hat{p}(I) ; I)=\frac{q_{n h}}{q_{n h}+q_{t h}}$, and $\hat{p}(I)=\frac{1}{2}\left(I(1+\alpha)+\frac{q_{t h}}{q_{n h}+q_{t h}} \pi\right)$.

Consider type $s=t h$. In the asserted equilibrium, he shall quote the price $\hat{p}(I)$, at which partner 2 sells. If partner 1 deviates, he can only change the outcome by quoting a lower price, $p<\hat{p}(I)$. However, this does not pay, since the gain from that deviation is negative:

$$
\begin{aligned}
\frac{I(1+\alpha)+\pi}{2}-(I+\pi-\hat{p}(I)) & =\alpha I-\frac{\pi}{2}+\frac{\pi q_{t h}}{2\left(q_{n h}+q_{t h}\right)} \\
& <0 .
\end{aligned}
$$

Consider $s=n h$. In the asserted equilibrium, he shall quote the price $\hat{p}(I)$, at which partner 2 sells. If partner 1 deviates, he can only change the outcome by quoting a lower price, $p<\hat{p}(I)$. However, this does not pay, since the gain from that deviation is obviously even smaller than the gain from the same deviation for type $t h$, which was already shown to be negative. 
Consider $s=l$. In the asserted equilibrium, partner 1 proposes the price $p_{1}$, and partner 2 vetoes. Partner 1 can only make a difference if he quotes a price $p=\hat{p}(I)$. However, the gain from that deviation is negative:

$$
I-\hat{p}(I)-\frac{I(1+\alpha)}{2}=-\frac{\pi q_{t h}}{2\left(q_{n h}+q_{t h}\right)}-\alpha I<0 .
$$

Proposition 4 The equilibrium strategies and beliefs of the "partial pooling equilibrium" for $I \in I_{3} \cup I_{4}$ are:

Strategies:

$$
\begin{gathered}
\sigma_{1}\left(p_{1} ; s, I\right):=1, \text { for all } s \in \Theta \\
\frac{I}{2} \leq p_{1}<\hat{p}(I):=\frac{1}{2}(I(1+\alpha)+\pi) \\
\sigma_{2}(p ; I)= \begin{cases}1 & \text { if } p \geq \hat{p}(I) \\
0 & \text { otherwise }\end{cases}
\end{gathered}
$$

Beliefs:

$$
\begin{aligned}
\delta_{t h}(p, I) & := \begin{cases}1 & \text { if } p \geq \hat{p}(I) \\
q_{t h} & \text { if } p \in\left[p_{1}, \hat{p}(I)\right) \\
0 & \text { otherwise }\end{cases} \\
\delta_{n h}(p, I): & = \begin{cases}q_{n h} & \text { if } p \in\left[p_{1}, \hat{p}(I)\right) \\
0 & \text { otherwise }\end{cases} \\
\delta_{l}(p, I) & := \begin{cases}q_{l} & \text { if } p \in\left[p_{1}, \hat{p}(I)\right) \\
1 & \text { if } p<p_{1} \\
0 & \text { otherwise }\end{cases}
\end{aligned}
$$

Proof The beliefs are obviously consistent with the stated strategies, using Bayes' rule, when it applies. Also, partner 2's strategy is evidently a best reply, given his beliefs. Partner 1 could only make a difference if he deviates and quotes a price $p \geq \hat{p}(I)$, at which partner 2 sells for sure. However, that never pays. 


\section{REFERENCES}

Banks, J. S., and Sobel, J. (1987). Equilibrium selection in signaling games. Econometrica, 55, 647-661.

Brooks, R., and Spier, K. E. (2004). Trigger happy or gun shy? Dissolving common-value partnerships with Texas shootouts (Discussion Paper). Kellogg School of Management.

Cho, I. K., and Kreps, D. (1987). Signaling games and stable equilibria. Quarterly Journal of Economics, 102, 179-221.

Cramton, P. C., Gibbons, R., and Klemperer, P. (1987). Dissolving a partnership efficiently. Econometrica, 55, 615-632.

de Frutos, M. A., and Kittsteiner, T. (2004). Efficient partnership dissolution under buy/sell clauses (Discussion Paper). Bonn Graduate School of Economics.

Farrell, J., and Scotchmer, S. (1988). Partnerships. Quarterly Journal of Economics, 103, 279-297.

Fieseler, K., Kittsteiner, T., and Moldovanu, B. (2003). Partnerships, lemons, and efficient trade. Journal of Economic Theory, 113, 223-234.

Grossman, S. J., and Hart, O. D. (1986). The costs and benefits of ownership: A theory of vertical and lateral integration. Journal of Political Economy, 94, 691-719.

Hauswald, R., and Hege, U. (2003). Ownership and control in joint ventures: Theory and evidence (Discussion Paper No. 4056). C.E.P.R.

Jehiel, P., and Pauzner, A. (2003). Partnership dissolution with interdependent values [Discussion Paper].

Kittsteiner, T. (2003). Partnerships and double auctions with interdependent valuations. Games and Economic Behavior, 44, 54-76. 
Mancuso, A., and Laurence, B. K. (2003). Buy-Sell Agreement Handbook: Plan Ahead for Changes in the Ownership of your Business. Nolo.com.

McAfee, R. P. (1992). Amicable divorce: Dissolving a partnership with simple mechanisms. Journal of Economic Theory, 56, 266-293.

Myerson, R. B., and Satterthwaite, M. A. (1983). Efficient mechanisms for bilateral trading. Journal of Economic Theory, 29, 265-281.

Nöldeke, G., and Schmidt, K. (1998). Sequential investments and options to own. Rand Journal of Economics, 29, 633-653.

Samuelson, W. (1984). Bargaining under asymmetric information. Econometrica, 52, 995-1005.

Wolfstetter, E. (2002). How to dissolve a partnership: Comment. Journal of Institutional and Theoretical Economics, 158, 86-90. 


\title{
CESifo Working Paper Series
}

\author{
(for full list see www.cesifo.de)
}

1265 Hans-Werner Sinn, Migration, Social Standards and Replacement Incomes. How to Protect Low-income Workers in the Industrialized Countries against the Forces of Globalization and Market Integration, August 2004

1266 Wolfgang Leininger, Fending off one Means Fending off all: Evolutionary Stability in Submodular Games, August 2004

1267 Antoine Bommier and Bertrand Villeneuve, Risk Aversion and the Value of Risk to Life, September 2004

1268 Harrie A. A. Verbon and Lex Meijdam, Too Many Migrants, Too Few Services: A Model of Decision-making on Immigration and Integration with Cultural Distance, September 2004

1269 Thomas Eichner and Rüdiger Pethig, Economic Land Use, Ecosystem Services and Microfounded Species Dynamics, September 2004

1270 Federico Revelli, Performance Rating and Yardstick Competition in Social Service Provision, September 2004

1271 Gerhard O. Orosel and Klaus G. Zauner, Vertical Product Differentiation When Quality is Unobservable to Buyers, September 2004

1272 Christoph Böhringer, Stefan Boeters, and Michael Feil, Taxation and Unemployment: An Applied General Equilibrium Approach, September 2004

1273 Assaf Razin and Efraim Sadka, Welfare Migration: Is the Net Fiscal Burden a Good Measure of its Economics Impact on the Welfare of the Native-Born Population?, September 2004

1274 Tomer Blumkin and Volker Grossmann, Ideological Polarization, Sticky Information, and Policy Reforms, September 2004

1275 Katherine Baicker and Nora Gordon, The Effect of Mandated State Education Spending on Total Local Resources, September 2004

1276 Gabriel J. Felbermayr and Wilhelm Kohler, Exploring the Intensive and Extensive Margins of World Trade, September 2004

1277 John Burbidge, Katherine Cuff and John Leach, Capital Tax Competition with Heterogeneous Firms and Agglomeration Effects, September 2004

1278 Joern-Steffen Pischke, Labor Market Institutions, Wages and Investment, September 2004 
1279 Josef Falkinger and Volker Grossmann, Institutions and Development: The Interaction between Trade Regime and Political System, September 2004

1280 Paolo Surico, Inflation Targeting and Nonlinear Policy Rules: The Case of Asymmetric Preferences, September 2004

1281 Ayal Kimhi, Growth, Inequality and Labor Markets in LDCs: A Survey, September 2004

1282 Robert Dur and Amihai Glazer, Optimal Incentive Contracts for a Worker who Envies his Boss, September 2004

1283 Klaus Abberger, Nonparametric Regression and the Detection of Turning Points in the Ifo Business Climate, September 2004

1284 Werner Güth and Rupert Sausgruber, Tax Morale and Optimal Taxation, September 2004

1285 Luis H. R. Alvarez and Erkki Koskela, Does Risk Aversion Accelerate Optimal Forest Rotation under Uncertainty?, September 2004

1286 Giorgio Brunello and Maria De Paola, Market Failures and the Under-Provision of Training, September 2004

1287 Sanjeev Goyal, Marco van der Leij and José Luis Moraga-González, Economics: An Emerging Small World?, September 2004

1288 Sandro Maffei, Nikolai Raabe and Heinrich W. Ursprung, Political Repression and Child Labor: Theory and Empirical Evidence, September 2004

1289 Georg Götz and Klaus Gugler, Market Concentration and Product Variety under Spatial Competition: Evidence from Retail Gasoline, September 2004

1290 Jonathan Temple and Ludger Wößmann, Dualism and Cross-Country Growth Regressions, September 2004

1291 Ravi Kanbur, Jukka Pirttilä and Matti Tuomala, Non-Welfarist Optimal Taxation and Behavioral Public Economics, October 2004

1292 Maarten C. W. Janssen, José Luis Moraga-González and Matthijs R. Wildenbeest, Consumer Search and Oligopolistic Pricing: An Empirical Investigation, October 2004

1293 Kira Börner and Christa Hainz, The Political Economy of Corruption and the Role of Financial Institutions, October 2004

1294 Christoph A. Schaltegger and Lars P. Feld, Do Large Cabinets Favor Large Governments? Evidence from Swiss Sub-Federal Jurisdictions, October 2004

1295 Marc-Andreas Mündler, The Existence of Informationally Efficient Markets When Individuals Are Rational, October 2004 
1296 Hendrik Jürges, Wolfram F. Richter and Kerstin Schneider, Teacher Quality and Incentives: Theoretical and Empirical Effects of Standards on Teacher Quality, October 2004

1297 David S. Evans and Michael Salinger, An Empirical Analysis of Bundling and Tying: Over-the-Counter Pain Relief and Cold Medicines, October 2004

1298 Gershon Ben-Shakhar, Gary Bornstein, Astrid Hopfensitz and Frans van Winden, Reciprocity and Emotions: Arousal, Self-Reports, and Expectations, October 2004

1299 B. Zorina Khan and Kenneth L. Sokoloff, Institutions and Technological Innovation During Early Economic Growth: Evidence from the Great Inventors of the United States, 1790 - 1930, October 2004

1300 Piero Gottardi and Roberto Serrano, Market Power and Information Revelation in Dynamic Trading, October 2004

1301 Alan V. Deardorff, Who Makes the Rules of Globalization?, October 2004

1302 Sheilagh Ogilvie, The Use and Abuse of Trust: Social Capital and its Deployment by Early Modern Guilds, October 2004

1303 Mario Jametti and Thomas von Ungern-Sternberg, Disaster Insurance or a Disastrous Insurance - Natural Disaster Insurance in France, October 2004

1304 Pieter A. Gautier and José Luis Moraga-González, Strategic Wage Setting and Coordination Frictions with Multiple Applications, October 2004

1305 Julia Darby, Anton Muscatelli and Graeme Roy, Fiscal Federalism, Fiscal Consolidations and Cuts in Central Government Grants: Evidence from an Event Study, October 2004

1306 Michael Waldman, Antitrust Perspectives for Durable-Goods Markets, October 2004

1307 Josef Honerkamp, Stefan Moog and Bernd Raffelhüschen, Earlier or Later: A General Equilibrium Analysis of Bringing Forward an Already Announced Tax Reform, October 2004

1308 M. Hashem Pesaran, A Pair-Wise Approach to Testing for Output and Growth Convergence, October 2004

1309 John Bishop and Ferran Mane, Educational Reform and Disadvantaged Students: Are They Better Off or Worse Off?, October 2004

1310 Alfredo Schclarek, Consumption and Keynesian Fiscal Policy, October 2004

1311 Wolfram F. Richter, Efficiency Effects of Tax Deductions for Work-Related Expenses, October 2004 
1312 Franco Mariuzzo, Patrick Paul Walsh and Ciara Whelan, EU Merger Control in Differentiated Product Industries, October 2004

1313 Kurt Schmidheiny, Income Segregation and Local Progressive Taxation: Empirical Evidence from Switzerland, October 2004

1314 David S. Evans, Andrei Hagiu and Richard Schmalensee, A Survey of the Economic Role of Software Platforms in Computer-Based Industries, October 2004

1315 Frank Riedel and Elmar Wolfstetter, Immediate Demand Reduction in Simultaneous Ascending Bid Auctions, October 2004

1316 Patricia Crifo and Jean-Louis Rullière, Incentives and Anonymity Principle: Crowding Out Toward Users, October 2004

1317 Attila Ambrus and Rossella Argenziano, Network Markets and Consumers Coordination, October 2004

1318 Margarita Katsimi and Thomas Moutos, Monopoly, Inequality and Redistribution Via the Public Provision of Private Goods, October 2004

1319 Jens Josephson and Karl Wärneryd, Long-Run Selection and the Work Ethic, October 2004

1320 Jan K. Brueckner and Oleg Smirnov, Workings of the Melting Pot: Social Networks and the Evolution of Population Attributes, October 2004

1321 Thomas Fuchs and Ludger Wößmann, Computers and Student Learning: Bivariate and Multivariate Evidence on the Availability and Use of Computers at Home and at School, November 2004

1322 Alberto Bisin, Piero Gottardi and Adriano A. Rampini, Managerial Hedging and Portfolio Monitoring, November 2004

1323 Cecilia García-Peñalosa and Jean-François Wen, Redistribution and Occupational Choice in a Schumpeterian Growth Model, November 2004

1324 William Martin and Robert Rowthorn, Will Stability Last?, November 2004

1325 Jianpei Li and Elmar Wolfstetter, Partnership Dissolution, Complementarity, and Investment Incentives, November 2004 